\title{
A review of multiple input DC-DC converter topologies linked with hybrid electric vehicles and renewable energy systems
}

\author{
Azuka Affam *, Yonis M. Buswig, Al-Khalid Bin Hj Othman, Norhuzaimin Bin Julai, Ohirul Qays \\ Department of Electrical and Electronic Engineering, Faculty of Engineering, Universiti Malaysia Sarawak, Kota Samarahan, Sarawak, 94300, Malaysia
}

\section{A R T I C L E I N F O}

\section{Keywords:}

Multi-input dc-dc converter

Renewable energy system

Hybrid electric vehicle

Double input

Topology

Renewable energy

Review

\begin{abstract}
A B S T R A C T
In this paper, the contemporary development in multiple input dc-dc converters are identified and examined. The quest to mitigate the difficulties associated with employing renewables in distribution systems and electric vehicles (EVs) has yielded many new converter topologies. These new topologies have easier control, lower parts count, are cheaper and are worthy alternatives to the typical series or parallel connection of converters. The converters are identified by three divisions that bother on the isolation between the respective ports. The electrically connected converters do not have isolation between the ports, and thus, a dc link connects the ports. Electromagnetically connected converters use a dc-link to connect input ports, but the input ports and output port are isolated. In magnetically connected converters, input ports are separated by multiple winding transformer, just as the output port is isolated from the input ports by the winding. The formation, structure, characteristics, operation, merits and demerits of the converters will be presented. Thereafter, comparisons will be done based on the distinct features of the converters. This review identifies that converter properties depend on the specific application requirement and thus, no converter fulfills all demands in the industry. Prospective future research trends are suggested. This work aims to update on research done during the time gap since the last comprehensive reviews.
\end{abstract}

\section{Introduction}

Recent developments have seen an unprecedented increase in efforts targeted at promoting, developing and managing renewable energy (RE) sources. Reasons for these are not far-fetched. Conventional energy sources (fossil fuels) have been classified as agents of environmental pollution and degradation, global warming, and greenhouse effect. These are mainly caused by gases emitted by the burning of these fossil fuels. This gas emission has aggravated the demand by environmentalists for definite action to mitigate the effects of fossil fuels on the environment. This intent to reduce emissions has led to the inevitable employment of RE sources for power generation.

In the transportation sector, conventional motor vehicles also pose challenges of environmental pollution and global warming. Ecological data sources in the United States reveal that transport-related machinery accounts for more than a quarter of the global warming emission gases [1]. The advent of the hybrid electric vehicle (HEV) has come to the fore, aiming to ameliorate transportation induced gas emissions. In HEVs, the use of multiple energy sources has been targeted to reduce operation cost and increase vehicle efficiency. RE sources have been identified as free, clean, and having low long-term maintenance costs. Despite the advantages offered by RE sources over fossil fuels, the former face challenges that continue to limit their application. Three scenarios highlight the importance of multi-input converters. Firstly, most RE sources typically have been found to possess low output voltage. This peculiarity hinders their application in hybrid systems where there is need for high voltage at the inverter level. Secondly, the stochastic nature of some variable RE sources implies unpredictability and inconsistency in quantity, reliability, and availability in the process of power generation. Thirdly, there are limits to the slew rate of some sources and storage devices like the fuel cell, batteries, and supercapacitor.

A panacea to these challenges is the combination of two or more RE sources and has given birth to the multi-input DC-DC converter. The general structure of a multiple input converter has been illustrated in Fig. 1. In the structure, instead of individual energy sources having their specific DC-DC converter, the routing is such that, all the input sources are directed to a common converter. In this condition, control of the input and output variables is central thereby reducing cost.

Structurally, converters can be identified by their isolation type. They could be either be isolated converters or non-isolated converters [2]. Isolation employs a transformer winding to transfer energy to the

\footnotetext{
* Corresponding author.

E-mail address: 18010014@siswa.unimas.my (A. Affam).
} 